\title{
Microstructural Evaluation and Ultrasonic Characterization of TLPD bonded 6061-SiCp Composite
}

\author{
Joydeep MAITY,1) Tapan Kumar PAL ${ }^{2)}$ and Rabindranath MAITI ${ }^{3)}$ \\ 1) Department of Metallurgical and Materials Engineering, National Institute of Technology, Durgapur, Durgapur-713209, \\ West Bengal, India. E-mail: joydeep_maity@yahoo.co.in $\quad$ 2) Welding Technology Center, Department of Metallurgical \\ and Material Engineering, Jadavpur University, Kolkata-700032, West Bengal, India. E-mail: tkpal.ju@gmail.com \\ 3) Central Research Facility, Indian Institute of Technology, Kharagpur-721302, West Bengal, India. \\ E-mail: maitirabin@yahoo.com
}

(Received on December 5, 2007; accepted on March 5, 2008)

\begin{abstract}
Microstructural evaluation during transient liquid phase diffusion (TLPD) bonding of extruded aluminium based metal matrix composite (6061-15 wt\% $\mathrm{SiC}_{\mathrm{p}}$ ) using $50 \mu \mathrm{m}$ thick copper interlayer was investigated by optical microscopy, scanning electron microscopy (SEM) together with SEM-based energy dispersive X-ray spectroscopy (EDS) and pulse echo ultrasonic test. Microstructural changes in the joint region were examined at five different holding time ( $20 \mathrm{~min}, 1 \mathrm{~h}, 2 \mathrm{~h}, 3 \mathrm{~h}$ and $6 \mathrm{~h}$ ) for a bonding temperature of $560^{\circ} \mathrm{C}$ under two different applied pressures (0.1 MPa and $0.2 \mathrm{MPa}$ ). Kinetics of the bonding process was significantly accelerated in presence of reinforcement $(\mathrm{SiC})$. This acceleration is attributed to the increased solute diffusivity through defect-rich $\mathrm{SiC}$ particle/matrix interface and porosity. The segregated particle at bond interface caused significant attenuation of ultrasonic wave, especially at lower bonding time. The attenuation effect decreased with increasing bonding time as width of particle segregation decreased.
\end{abstract}

KEY WORDS: transient liquid phase diffusion bonding; 6061-SiCp composite; mechanism; particle segregation; isothermal solidification; homogenization; process kinetics; dislocation; diffusion; ultrasonic attenuation.

\section{Introduction}

Aluminium based metal matrix composites (AlMMC) possess superior properties to the aluminium alloys, such as increased stiffness, high strength, good wear resistance and enhanced creep resistance which make these composites suitable for aerospace and transport industry applications. ${ }^{1,2)}$ The main hindrance of widespread industrial application of AlMMC is the difficulty encountered in their joining. ${ }^{3)}$ Mechanical fastening(bolting and riveting) involves damage of reinforcement and generation of stress concentration leading to catastrophic failure. ${ }^{4)}$ Fusion welding of $\mathrm{SiC}$ reinforced AlMMC imposes problems such as formation of detrimental intermetallic compound $\left(\mathrm{Al}_{4} \mathrm{C}_{3}\right)$, weld porosity, cracking at HAZ etc. ${ }^{5-7)}$ Diffusion bonding has been recognized as the precision bonding technique for metals, non-metals, dissimilar materials and metal matrix composites. ${ }^{899}$ There are two diffusion bonding techniques: solid state diffusion bonding and transient liquid phase diffusion (TLPD) bonding. Solid state diffusion bonding of AlMMC requires application of high pressure to remove tenacious and stable aluminium oxide layer at surface that inhibits metal to metal contact. Such high pressure causes substantial plastic deformation (in excess of $40 \%$ ). ${ }^{10,11)}$ The transient liquid phase diffusion (TLPD) bonding process which employs an 'interlayer' (often a pure metal) for the formation of low melting point composition (e.g. eutectic), has the advantage of lower bonding temperature, lower bonding pressure and less surface finish requirement than solid state diffusion bonding. However, completion of the TLPD bonding process requires a long time mainly due to isothermal solidification stage. If isothermal solidification is not completed, residual liquid in the interlayer may solidify as brittle phases impairing bond strength. ${ }^{12)}$ For commercial application of this technique, understanding the microstructural variation in the bond region with respect to kinetics of the TLPD process particularly during isothermal solidification is of great importance.

Although a number of investigations have been carried out on TLPD bonding of different monolithic metals and alloys, reports on the TLPD bonding of AlMMCs are limited. ${ }^{9,13-16)}$ Furthermore, among different interlayer used in TLPD bonding of monolithic aluminium based alloys, the use of copper interlayer has proved to be successful for joining conventional aluminium alloys, and bond strength comparable to that of the parent material has been reported. ${ }^{17)}$ Again, the published literature on TLPD bonding of AlMMCs mainly dealt with the development of bonding conditions using different thickness of copper interlayer in order to achieve adequate bond strength. However, no explicit correlation was made between bond microstructure and different stages of the process. Also, no comparison of process kinetics was made with monolithic system. This is particularly important since AlMMC rein- 
forced with ceramic particles exhibits a high dislocation density and defect-rich particle/matrix interface as compared to monolithic aluminium alloys. ${ }^{18)}$ Therefore, the presence of $\mathrm{SiC}$ particle is expected to accelerate TLPD bonding process of AlMMC.

On the other hand, accurate control of product quality is crucial for any particular application of AlMMC using the TLPD process. Further, there would be major benefits if non-destructive testing (NDT) is applied to assess bond quality. Among different NDT methods, the potential of ultrasonic testing is now recognized universally. For example, the ultrasonic immersion method has been developed to determine stiffness constants of $\mathrm{Al} / \mathrm{SiCp}$ composite. ${ }^{19)}$ However, rarely any published literature is available that characterizes the bond region of TLPD bonded AlMMC by conventional nondestructive technique. The purpose of the present work is to study the microstructure of TLPD bonded 6061-SiCp composite with regard to process kinetics and mechanism in comparison with the reported process kinetics and mechanism in monolithic system, as well as to investigate bond region by conventional pulse echo ultrasonic technique.

\section{Experimental Procedure}

\subsection{Material}

As-received material was an extruded rod of AlMMC consisting of 6061 matrix alloy and $15 \mathrm{wt} \%$ (12.93 vol\%) silicon carbide $(\mathrm{SiC})$ particulate reinforcement of $23 \mu \mathrm{m}$ average size. The nominal composition of 6061 alloy $^{20)}$ is given in Table 1. In addition it contains some iron (0.6 $\mathrm{wt} \%$ ) as an impurity which was confirmed by optical emission spectroscopy. The density of this as received AlMMC was also measured by water displacement method.

\subsection{Specimen Preparation for Bonding}

The extruded rod was machined to produce discs of $15 \mathrm{~mm}$ diameter and $10 \mathrm{~mm}$ height. As a result the flat surfaces of discs became perpendicular to the extrusion direction. The flat surfaces of discs to be joined together were polished to $1 \mu \mathrm{m}$ finish. Pure copper (99.97 wt\%) foil of $50 \mu \mathrm{m}$ thickness was used as interlayer. The interlayer was punched out to a diameter of $15 \mathrm{~mm}$ for bonding. The interlayer and polished flat surfaces of discs were finally rinsed in acetone and dried by a hot air blast just before bonding.

\subsection{TLPD Bonding}

The interlayer was placed between the polished faying surfaces of the two AlMMC discs. This assembly was then set by an adhesive tape and inserted inside the diffusion bonding unit. The bonding was carried out in a programmable electric furnace keeping bond centerline horizontal. A thermocouple inserted into the drilled hole in one of each pair of discs was used to monitor bonding temperature. The argon gas was flown into the bonding chamber at a rate $5 \mathrm{~L} / \mathrm{min}$ to maintain inert atmosphere. The bonding temperature was kept at $560^{\circ} \mathrm{C}$ which is above the eutectic temperature $\left(548^{\circ} \mathrm{C}\right)$ of $\mathrm{Al}-\mathrm{Cu}$ system $^{21)}$ and below the solidus temperature $\left(582^{\circ} \mathrm{C}\right)$ of 6061 matrix alloy. ${ }^{20)}$ The specimens were heated to the bonding temperature $\left(560^{\circ} \mathrm{C}\right)$ at a rate of $6^{\circ} \mathrm{C} / \mathrm{min}$, held at that temperature for five different lengths
Table 1. Chemical composition of 6061 alloy (wt \%).

\begin{tabular}{|l|l|l|l|l|}
\hline $\mathrm{Mg}$ & $\mathrm{Si}$ & $\mathrm{Cu}$ & $\mathrm{Cr}$ & $\mathrm{Al}$ \\
\hline 1.0 & 0.6 & 0.3 & 0.2 & rest \\
\hline
\end{tabular}

of time (bonding time) viz. $20 \mathrm{~min}, 1 \mathrm{~h}, 2 \mathrm{~h}, 3 \mathrm{~h}, 6 \mathrm{~h}$ and cooled down to a temperature of $540^{\circ} \mathrm{C}$ inside the furnace. Then the specimens were taken out of the furnace and cooled in still air to the room temperature. Two different pressures, $0.1 \mathrm{MPa}$ and $0.2 \mathrm{MPa}$, were applied for bonding.

\subsection{Optical Metallography}

Bonded cylindrical samples were sectioned perpendicular to the bonding plane using a low speed diamond cutter. The section was polished to $1 \mu \mathrm{m}$ finish and etched with Keller's reagent. Both qualitative and quantitative study of microstructure around bond interface was carried out using optical microscope with digital photomicrography (ZEISS, Imager.A1m). The interface width was measured at 'periphery' and 'central zone' of the bond interface. The bond centerline had $15 \mathrm{~mm}$ length. The two edges of bond centerline, with each edge of $3.5 \mathrm{~mm}$ length, were considered as 'periphery'. The remaining part at the middle, of $8 \mathrm{~mm}$ length, was considered as 'central zone'.

\subsection{SEM and EDS Analysis}

As-polished section was examined around bond interface under scanning electron microscope (JEOL, JSM-5800). Microstructures were studied with both back scattered electron image mode and secondary electron image mode. Reasonable phase contrast was achieved in back scattered electron image mode. Accordingly different phases were identified by EDS spot analysis. Also the progress of diffusion was studied by line scan. The line scan for concentration variation of copper was carried out along a line of $600 \mu \mathrm{m}$ length lying perpendicular to the bond interface keeping bond centerline approximately at the middle.

\subsection{Ultrasonic Test}

Bonded cylindrical samples were machined to $10 \mathrm{~mm}$ diameter to eliminate edge effects. Flat surfaces at the two ends were polished with fine emery paper. These bonded specimens having dimension of $20 \mathrm{~mm}$ length (approximately) $\times 10 \mathrm{~mm}$ diameter and as received composite specimen of similar dimension were taken for Ultrasonic test. The test was carried out in a pulse echo ultrasonic instrument (KARL DEUTSCH-ECOGRAPH 1030) at a frequency of $10 \mathrm{MHz}$ using TR probe. During test the longitudinal wave propagated approximately perpendicular to the bonding plane (along the length of the specimen).

\section{Results and Discussion}

\subsection{As-received Composite}

The microstructure of as-received AlMMC as shown in Fig. 1 clearly reveals bands of SiC-rich areas along the extrusion direction as well as some porosity near the particle cluster (band). The presence of porosity is also indicated in the measured density of the composite $\left(2.72 \mathrm{~g} / \mathrm{cm}^{3}\right)$ that shows lower value than the theoretical density of composite $\left(2.77 \mathrm{~g} / \mathrm{cm}^{3}\right)$ based on the calculation from the 


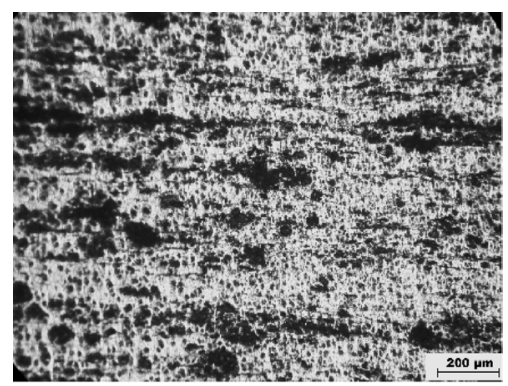

(a)

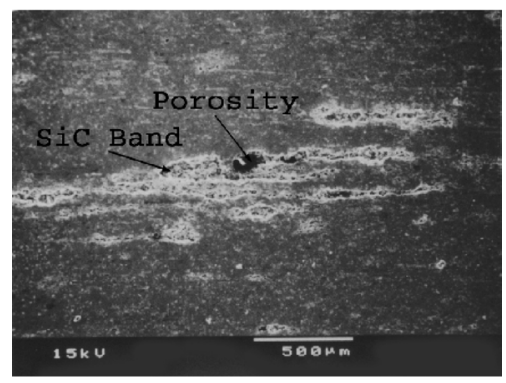

(b)

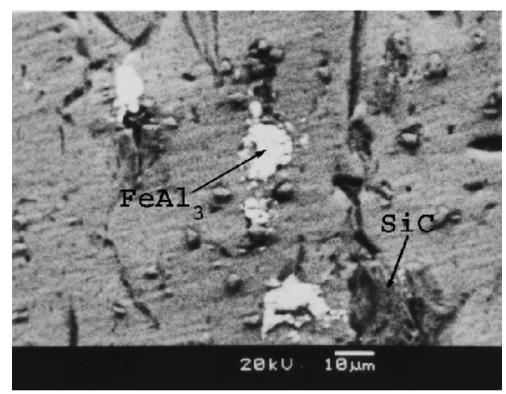

(c)

Fig. 1. Microstructure of as received 6061-SiCp composite. (a) Optical image: bands of $\mathrm{SiC}$ along extrusion direction. (b) SEM secondary electron image: $\mathrm{SiC}$ bands and porosity. (c) SEM back scattered image: Presence of $\mathrm{FeAl}_{3}$.

reported density ${ }^{20,22)}$ of 6061 matrix alloy $\left(2.70 \mathrm{~g} / \mathrm{cm}^{3}\right)$ and $\mathrm{SiC}\left(3.21 \mathrm{~g} / \mathrm{cm}^{3}\right)$. The presence of bright $\mathrm{FeAl}_{3}$ intermetallic phase (containing about $61 \mathrm{wt} \% \mathrm{Al}$ ) in AlMMC is confirmed by SEM back scattered image (Fig. 1(c)) and EDS Spot analysis (Fig. 2(a)). Chemical analysis by Optical emission spectrometer indicates the presence of about $0.6 \mathrm{wt} \%$ iron impurity in the composite. The presence of iron impurity (about $0.7 \mathrm{wt} \% \mathrm{Fe}$ ) in 6061 alloy was reported. ${ }^{23)}$ Also, the presence of $\mathrm{FeAl}_{3}$ in AlMMC containing iron impurity was observed. ${ }^{14)}$ The formation of $\mathrm{FeAl}_{3}$ phase even for iron content less than $0.6 \mathrm{wt} \%$ is not unexpected since iron has got very little solubility in aluminium as confirmed from $\mathrm{Fe}-\mathrm{Al}$ phase diagram. ${ }^{21)}$

\subsection{Microstructural Evaluation and Mechanism}

Optical microstructures of TLPD bonded specimens in etched condition representing the bond interface at central zone is shown in Fig. 3. SEM back scattered images of the bond interface are presented in Figs. 4 and 5. The specimens with minimum bonding time $(20 \mathrm{~min})$ exhibit isothermally solidified grains (mainly of primary $\alpha$ ) adjacent to bond interface (Fig. 3(a)). Furthermore, presence of $\mathrm{CuAl}_{2}$ phase (containing about $54 \mathrm{wt} \% \mathrm{Cu}$ ) is observed (Fig. 4(a)) adjacent to the bond interface. It is to be noted that as-

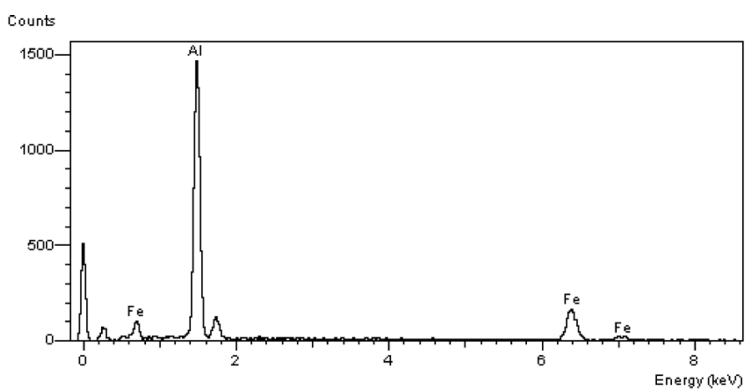

(a)

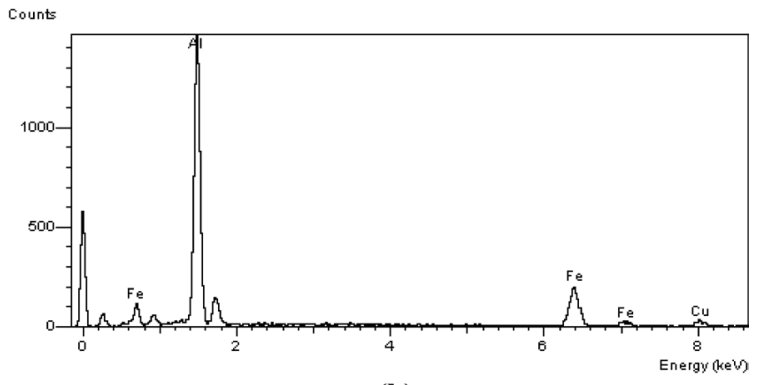

(b)

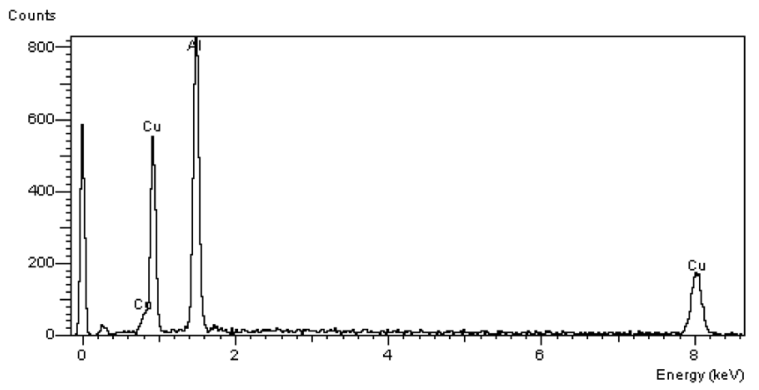

(c)

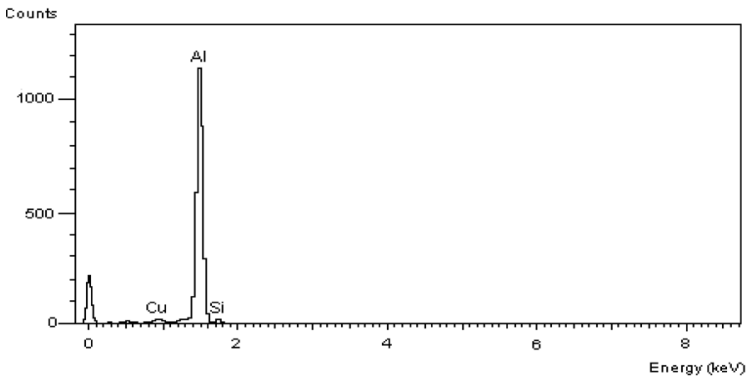

(d)

Fig. 2. EDS pattern for different phases. (a) $\mathrm{FeAl}_{3}$ in as received composite. (b) $\mathrm{Fe}_{2} \mathrm{Al}_{5}$ in bonded composite. (c) $\mathrm{CuAl}_{2}$ phase in bonded composite. (d) Primary $\alpha$ containing $2.11 \mathrm{wt} \% \mathrm{Cu}$ at bond centerline $(0.2 \mathrm{MPa}, 3 \mathrm{~h})$.

received AlMMC (unbonded) does not contain any $\mathrm{CuAl}_{2}$ intermetallic phase. This observation indicates that isothermal solidification started before $20 \mathrm{~min}$ of bonding time and $\mathrm{CuAl}_{2}$ phase is likely to precipitate out in isothermally solidified zone during cooling from bonding temperature as solubility of $\mathrm{Cu}$ in primary $\alpha$ decreases with decreasing temperature following solvus curve.

Based on the study of monolithic system, the TLPD bonding process was described as consisting of four stages by previous investigators ${ }^{12,24,25)}$ namely, (I) dissolution of interlayer, (II) homogenization of liquid (widening of liquid to its maximum width), (III) isothermal solidification, and (IV) homogenization of bond region. Liu et al. ${ }^{26)}$ outlined an analytical model that accounts for the fact that the disso- 


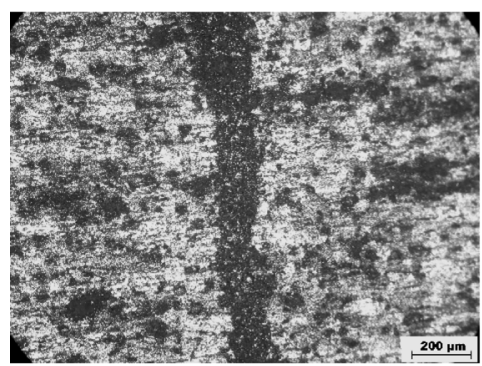

(a) 20 minutes

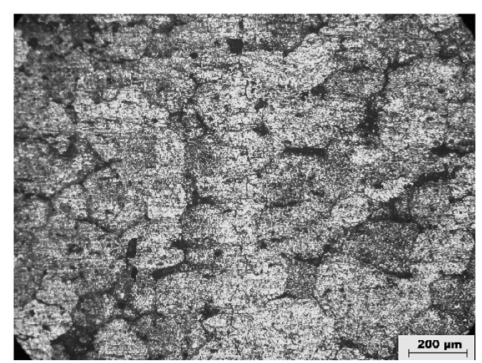

(d) 3 hours

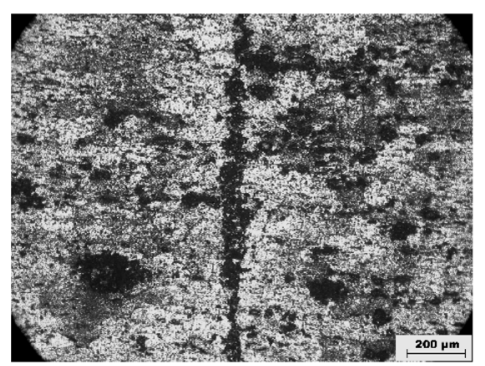

(b) 1 hour

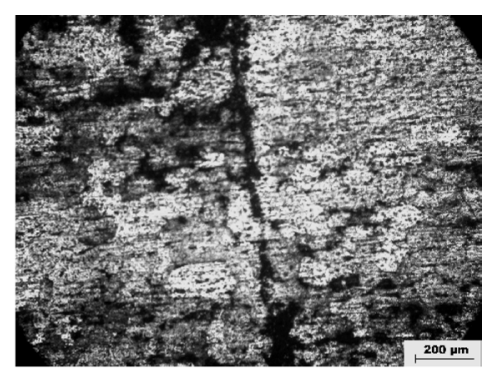

(c) 2 hours

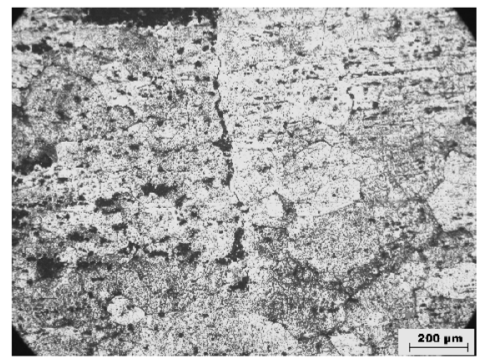

(e) 6 hours

Fig. 3. Typical optical microstructures of bonded specimens at central zone of bond interface at $0.2 \mathrm{MPa}$ pressure.

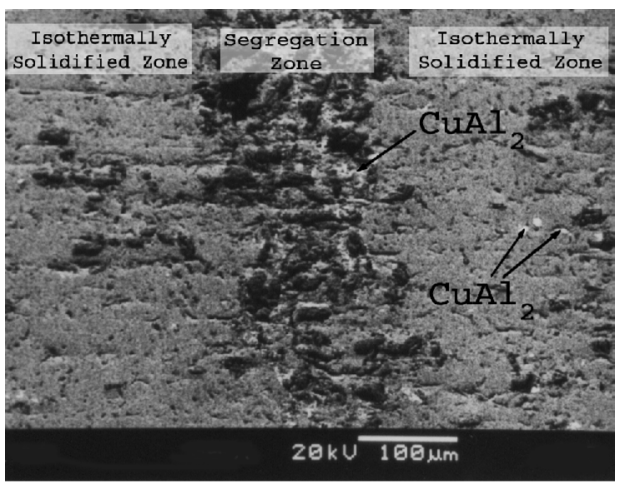

(a) 20 minutes, $0.2 \mathrm{MPa}$

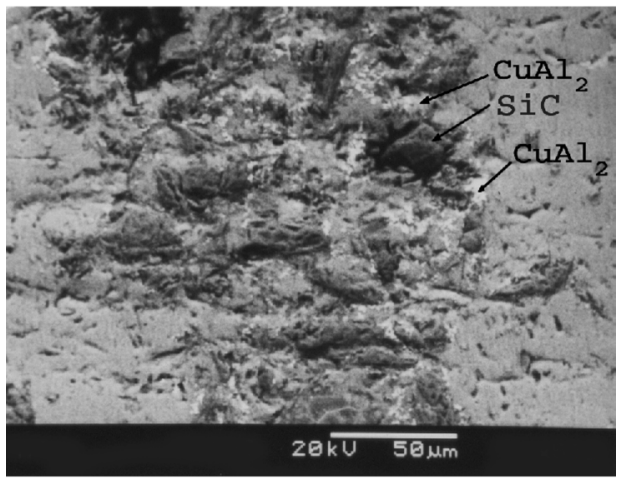

(b) 20 minutes, $0.2 \mathrm{MPa}$ (higher magnification)

Fig. 4. SEM backscattered image of bonded specimens with lower bonding time.

lution front proceeds into the interlayer as well as the parent metal. Using Liu et al.'s equations the time for complete dissolution of the interlayer is of the order of seconds, as was also calculated by Tuah-Poku et al. ${ }^{25)}$ However, analytical models have not been developed to fully describe the widening process of liquid (stage II) and, in fact, there is no discrete boundary in time between stage I and stage II. Once the interlayer is dissolved, the width of the liquid zone becomes greater than the initial interlayer width.

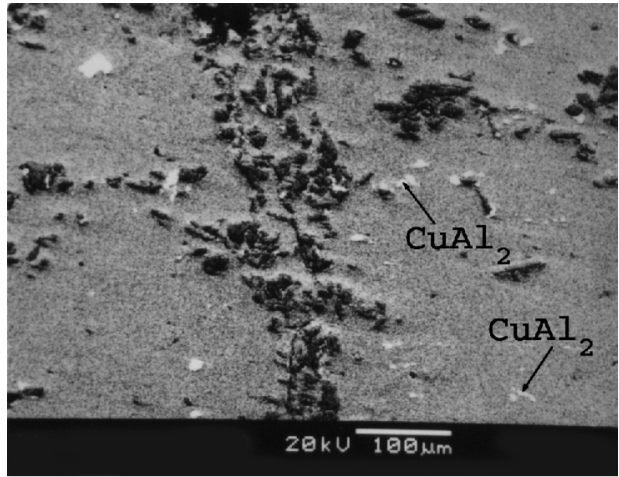

(a) 3 hours, 0.1 MPa (near periphery).

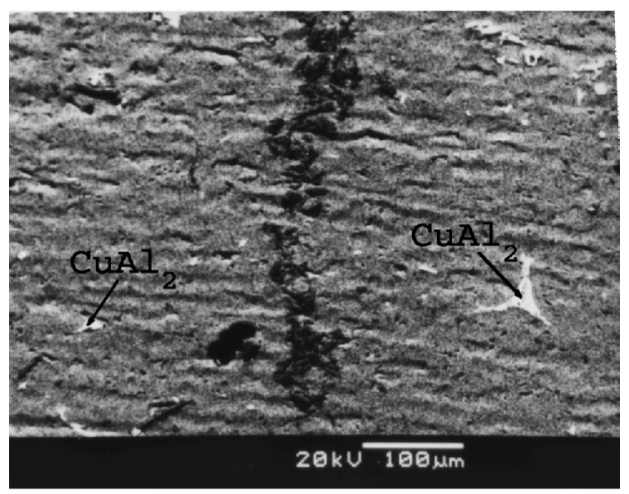

(b) 3 hours, $0.2 \mathrm{MPa}$ (near periphery)

Fig. 5. SEM backscattered image of bonded specimens with higher bonding time.

Hence the process of widening occurs concurrently with dissolution. Nakao et al. ${ }^{27)}$ and Tuah-Poku et al. ${ }^{25)}$ reported that the time required for the liquid widening process (stage II) is of the order of minutes. In present study, heating from eutectic temperature $\left(548^{\circ} \mathrm{C}\right)$ to the bonding temperature $\left(560^{\circ} \mathrm{C}\right)$ at a rate $6^{\circ} \mathrm{C} / \mathrm{min}$ takes $2 \mathrm{~min}$. It is possible that the first two stages (dissolution of interlayer and widening of liquid) are completed during heating to the bonding temperature. Therefore, liquid widening process completes and 
isothermal solidification starts before $20 \mathrm{~min}$ of holding.

The presence of $15 \mathrm{wt} \% \mathrm{SiC}$ particle in 6061 aluminium matrix is expected to have significant effect on TLPD bonding process as compared to pure monolithic system. Microstructural study reveals the segregation of $\mathrm{SiC}$ particles at bond centerline with isothermally solidified zones on both sides. During bonding the bond centerline was kept horizontal. Since no preferential segregation occurs towards the lower AlMMC disc, this is not the case of gravity segregation. According to published literature ${ }^{28)}$ on general solidification characteristic of $\mathrm{SiC}$ reinforced AlMMC, the primary $\alpha$ is very efficient at rejecting $\mathrm{SiC}$, and pushing the particles ahead of the solid/liquid interface. In this regard a critical velocity of solid/liquid interface has been reported, ${ }^{23)}$ below which the $\mathrm{SiC}$ particles are pushed by the moving interface and above which they are entrapped. Since the first two stages of TLPD bonding (dissolution of interlayer and widening of liquid) are very fast the velocity of solid/liquid interface is also very high. As a result $\mathrm{SiC}$ particles are not pushed by the solid/liquid interface away from the bond centerline during widening of liquid. The next stage, the isothermal solidification, is slow due to solid state diffusion controlling the process and takes several hours for completion. During isothermal solidification due to low velocity of solid/liquid interface most of the $\mathrm{SiC}$ particles are pushed by the moving solid/liquid interface, as evident in the present work. As a result, particles segregate at bond centerline along with liquid phase and the residual liquid gets solidified during cooling. This aggregate of residual liquid and segregated $\mathrm{SiC}$ particles may be called as 'Segregation Zone' and the width of this segregation zone may be termed as 'interface width'. This is schematically shown in Fig. 6. The measured interface width at central zone and at periphery of bond interface is presented in Table 2. At $20 \mathrm{~min}$ bonding time the interface width at central zone is somewhat similar (slightly greater) to that at periphery. However, with increasing bonding time interface width at central zone decreases continuously and always remains lower than that at periphery. This phenomenon indicates that during TLPD bonding under pressure (0.1 MPa and 0.2 MPa) liquid-particle aggregate at interface moves towards periphery and flows out. The interface width at periphery exhibits decrease and occasional increase depending on the flow of liquid-particle aggregate from center to periphery and from periphery to outside. Also, with increasing bonding time reduction of interface width at central zone is more at higher pressure $(0.2 \mathrm{MPa})$ than at lower pressure $(0.1 \mathrm{MPa})$. This again indicates more mass flow towards periphery under higher pressure. It is important to note that specimens with $3 \mathrm{~h}$ and $6 \mathrm{~h}$ bonding time (for both the pressures $0.1 \mathrm{MPa}$ and $0.2 \mathrm{MPa}$ ) exhibit negligible interface width at central zone with least segregation of SiC particles as shown in Figs. 3(d) and 3(e). Furthermore, the bond interface is hardly discernible and grain continuity exists across the interface indicating the completion of isothermal solidification in $3 \mathrm{~h}$ of bonding time. The EDS spot analysis (Fig. 2(d)) at bond interface of the specimen with $3 \mathrm{~h}$ bonding time and $0.2 \mathrm{MPa}$ pressure exhibits the presence of $2.11 \mathrm{wt} \% \mathrm{Cu}$. According to $\mathrm{Al}-\mathrm{Cu}$ phase diagram, ${ }^{21)}$ at bonding temperature $\left(560^{\circ} \mathrm{C}\right)$ the maximum solubility of copper in primary $\alpha$ is $4.35 \mathrm{wt} \%$. Therefore,

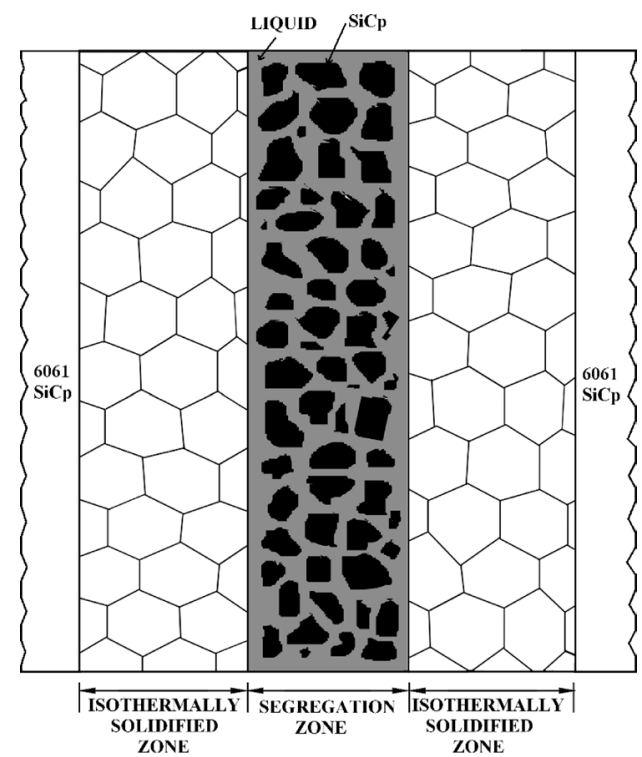

Fig. 6. Schematic representation of bond region during isothermal solidification.

Table 2. Interface width at central zone and periphery.

\begin{tabular}{|c|l|c|c|}
\hline \multirow{2}{*}{ Bonding Pressure } & \multirow{2}{*}{ Bonding Time } & \multicolumn{2}{|c|}{ Interface width $(\mu \mathrm{m})$} \\
\cline { 3 - 4 } & & at Central Zone & at periphery \\
\hline \multirow{5}{*}{$0.1 \mathrm{MPa}$} & 20 minutes & 230 & 185 \\
\cline { 2 - 4 } & 1 hour & 107 & 177 \\
\cline { 2 - 4 } & 2 hours & 93 & 183 \\
\cline { 2 - 4 } & 3 hours & Negligible & 163 \\
\cline { 2 - 4 } & 6 hours & Negligible & 143 \\
\hline \multirow{5}{*}{$0.2 \mathrm{MPa}$} & 20 minutes & 223 & 205 \\
\cline { 2 - 4 } & 1 hour & 86 & 173 \\
\cline { 2 - 4 } & 2 hours & 73 & 171 \\
\cline { 2 - 4 } & 3 hours & Negligible & 196 \\
\cline { 2 - 4 } & 6 hours & Negligible & 134 \\
\hline
\end{tabular}

the copper content of $2.11 \mathrm{wt} \%$ indicates the presence of primary $\alpha$ grains. This further confirms the completion of isothermal solidification.

However, so far, TLPD bonding process in relation to its process mechanism has been rarely dealt in the joining of AlMMC. Also, literature on TLPD bonding mechanism specifically for joining pure aluminium or aluminium alloys using $\mathrm{Cu}$ interlayer is limited. Natsume et al. $^{12)}$ investigated the mechanism of TLPD bonding for joining pure Al by $50 \mu \mathrm{m} \mathrm{Cu}$ interlayer at $570^{\circ} \mathrm{C}$ up to a maximum bonding time of $1 \mathrm{~h}$. According to their experimental data, melting of interlayer took about $15 \mathrm{~s}$. The liquid widened to its maximum width of $460 \mu \mathrm{m}$ in $60 \mathrm{~s}$. It is to be noted that the specimen was not held at bonding temperature till the completion of isothermal solidification. Up to $1 \mathrm{~h}$ of maximum holding liquid width decreased to $406 \mu \mathrm{m}$ through isothermal solidification. Whereas, in the present investigation interface width at central zone has reduced to $107 \mu \mathrm{m}$ for $0.1 \mathrm{MPa}$ pressure and $86 \mu \mathrm{m}$ for $0.2 \mathrm{MPa}$ pressure after $1 \mathrm{~h}$ of holding. This indicates much faster kinetics of isothermal solidification in case of AlMMC as compared to the pure monolithic system. In the present study AlMMC contains substantial amount $(15 \mathrm{wt} \%)$ of $\mathrm{SiC}$ particles. The presence of $\mathrm{SiC}$ particles in the metallic matrix leads to the formation of defect-rich interfacial region of high dislocation density, mainly due to the difference in coefficient of thermal expansion between metallic matrix and $\mathrm{SiC}$ parti- 


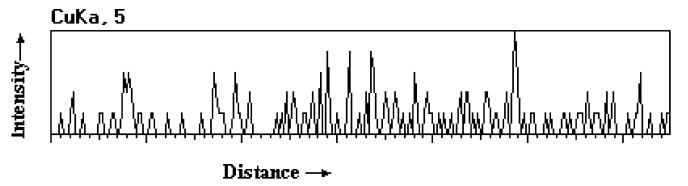

(a) 20 minutes

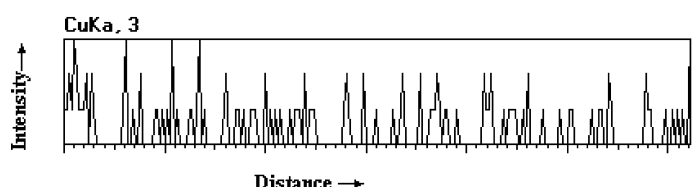

(b) 1 hour

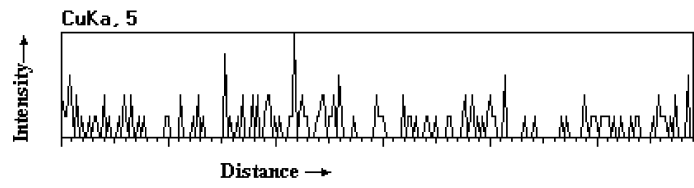

(c) 2 hours

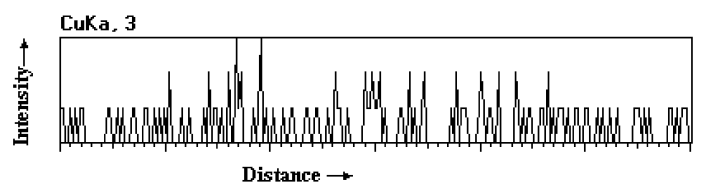

(d) 3 hours

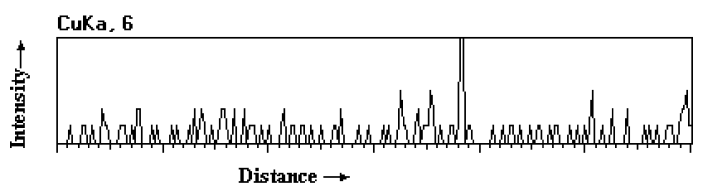

(e) 6 hours

Fig. 7. Line scan results representing concentration variation of $\mathrm{Cu}$ around bond interface at $0.1 \mathrm{MPa}$ pressure (X-axis length $=600 \mu \mathrm{m})$.

cles. ${ }^{18,30-33)}$ The coefficient of thermal expansion of 6061 matrix alloy and $\mathrm{SiC}$ particle are $23.6 \times 10^{-6} / \mathrm{K}$ and $5.5 \times$ $10^{-6} / \mathrm{K}$ respectively. ${ }^{20,22)}$ Thus, it is likely that the particle/ matrix interface of composite is associated with high dislocation density. In addition, as discussed earlier, the composite contains porosity. These defects provide short circuit paths for diffusion. Therefore, at the bonding temperature of $560^{\circ} \mathrm{C}$ (which is nearer to the solidus temperature, $582^{\circ} \mathrm{C}$, of 6061 alloy), along with lattice diffusion, short circuit diffusion is also expected to be operative. It is reported that ${ }^{34)}$ short circuit diffusivities are larger than lattice diffusivities by a factor of $10^{3}$ near the melting point. As a result, diffusion becomes faster. Moreover, due to application of pressure some part of liquid flows out of periphery reducing the amount of liquid to be solidified isothermally.

The result of line scan (Fig. 7) for $\mathrm{Cu}$ concentration variation across the bond interface indicates diffusion of $\mathrm{Cu}$ away from the interface. At the bonding time of $6 \mathrm{~h} \mathrm{Cu}$ is found to be uniformly distributed representing homogenization of bond region. The $\mathrm{CuAl}_{2}$ phase is found to be present at bond interface (segregation zone) as well as in isothermally solidified zone. At the bond interface $\mathrm{CuAl}_{2}$ forms through eutectic solidification of residual liquid during cooling. At the bonding temperature this residual liquid re-

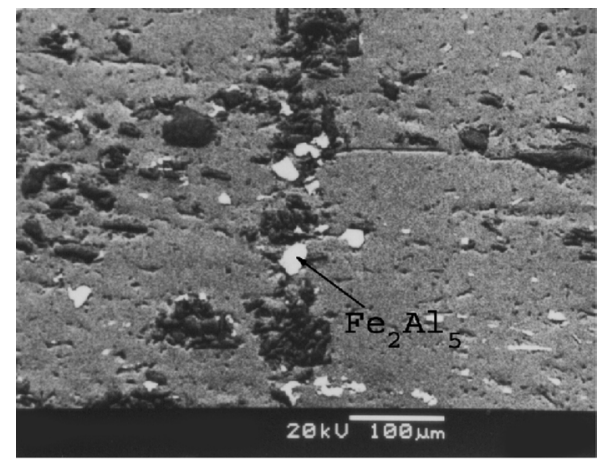

(a) 1 hour, $0.2 \mathrm{MPa}$ (near central zone)

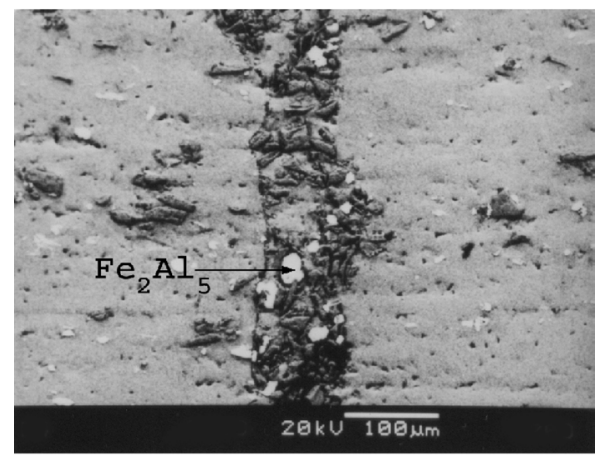

(b) 6 hours, $0.2 \mathrm{MPa}$ (near periphery)

Fig. 8. Segregation of $\mathrm{Fe}_{2} \mathrm{Al}_{5}$ at bond interface.

mains intermixed with segregated SiC particles. SEM backscattered image (Fig. 4) clearly reveals that during cooling $\mathrm{CuAl}_{2}$ preferentially nucleates on $\mathrm{SiC}$ particles at bond interface. Lower is the bonding time more $\mathrm{CuAl}_{2}$ phase is present at bond interface than in isothermally solidified zone. As bonding time increases further diffusion of $\mathrm{Cu}$ away from the bond interface gradually ceases $\mathrm{CuAl}_{2}$ formation at interface. For higher bonding time (Fig. 5) $\mathrm{CuAl}_{2}$ phase is mostly found to appear in the isothermally solidified zone away from the interface. Isothermally solidified zone contains the grains of primary $\alpha$. During cooling from bonding temperature, as the solubility of $\mathrm{Cu}$ decreases, $\mathrm{CuAl}_{2}$ precipitates out of primary $\alpha$. In bonded composite the intermetallic phase of iron impurity is found to be present in the form of $\mathrm{Fe}_{2} \mathrm{Al}_{5}$. The pebble shaped $\mathrm{Fe}_{2} \mathrm{Al}_{5}$ (containing $56 \mathrm{wt} \% \mathrm{Al}$ ) segregates mainly at bond interface (Fig. 8). It is likely that during isothermal solidification $\mathrm{Fe}_{2} \mathrm{Al}_{5}$ particles are pushed by solid/liquid interface and thereby segregate at bond interface (segregation zone) along with $\mathrm{SiC}$ particles. The high melting point of $\mathrm{Fe}_{2} \mathrm{Al}_{5}$ $\left(1169^{\circ} \mathrm{C}\right)$ and the stability of $\mathrm{Fe}_{2} \mathrm{Al}_{5}$ phase around bonding temperature $\left(560^{\circ} \mathrm{C}\right)$ as obtained from the phase diagrams of binary $\mathrm{Fe}-\mathrm{Al}$ and ternary $\mathrm{Al}-\mathrm{Cu}-\mathrm{Fe}$ systems $^{21,35)}$ further confirms this possibility.

\subsection{Ultrasonic Characterization}

The typical display on oscilloscope screen for ultrasonic test is shown in Fig. 9. The ratio of back wall echo height (h) to initial pulse height $\left(h_{0}\right)$ is calculated. This ratio $\left(h / h_{0}\right)$ is considered to be the ratio of the amplitude of back wall echo to the amplitude of initial pulse. The attenuation coefficient $(\beta)$ referred to sound pressure is expressed in $\mathrm{dB} / \mathrm{m}$ as $^{36)}: \beta=(20 / L) \log \left(P_{0} / P\right)$; where ' $L$ ' is the total distance in 


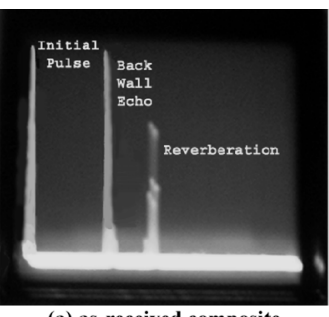

(a) as-received composite

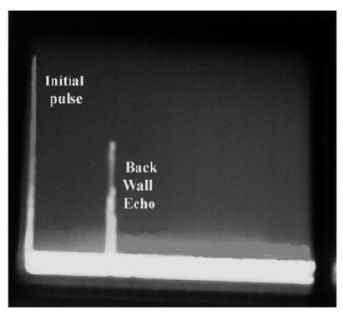

(c) 1 hour

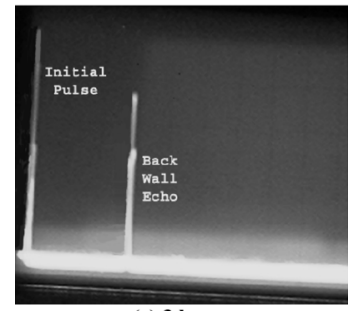

(e) 3 hours

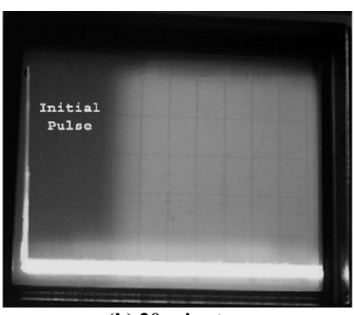

(b) 20 minutes

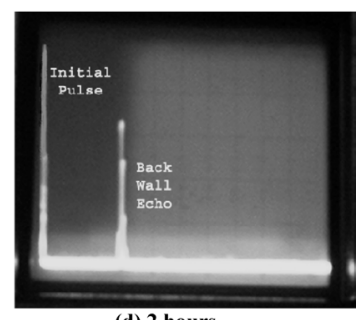

(d) 2 hours

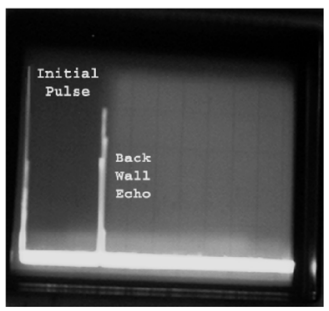

(f) 6 hours
Fig. 9. Typical oscilloscope display for ultrasonic test of as-received composite and specimens bonded at $0.2 \mathrm{MPa}$ pressure.

' $\mathrm{m}$ ' traveled by the ultrasonic wave which is equal to the length of the specimen. $P_{0}$ and $P$ are the sound pressures at the beginning and the end, respectively. Since sound pressure is proportional to the amplitude, $\left(P_{0} / P\right)$ is replaced by $\left(h_{0} / h\right)$ and accordingly attenuation coefficient $(\beta)$ is calculated. Table 3 summarizes the calculated $\beta$ values for different specimens. The back wall echo height for as received composite is almost equal to the height of initial pulse and corresponding attenuation coefficient is very small $(9 \mathrm{~dB} / \mathrm{m})$. This indicates that scattering of ultrasonic wave by $\mathrm{SiC}$ particles in as received composite is insignificant and therefore, attenuation is negligible. For $10 \mathrm{MHz}$ test frequency and with a sound velocity $6.32 \times 10^{3} \mathrm{~m} / \mathrm{s}$ in aluminium, ${ }^{36)}$ wave length of ultrasound comes out to be 632 $\mu \mathrm{m}$. The average particle size of composite $(23 \mu \mathrm{m})$ is therefore less than $1 / 10$ th of the wavelength $(63 \mu \mathrm{m})$. Under this condition attenuation is usually absent. ${ }^{36)}$ Also, in as received composite, the $\mathrm{SiC}$ bands are parallel to the direction of the ultrasonic wave propagation and therefore, should not cause attenuation.

However, in bonded specimens, significant attenuation is observed, especially at shorter bonding time. The Specimens with $20 \mathrm{~min}$ bonding time at both the applied pressures (0.1 MPa and 0.2 $\mathrm{MPa}$ ) do not exhibit any back wall echo indicating complete attenuation. For longer bonding times back wall echo appears and its height increases with increasing bonding time. Therefore, with increasing bonding time the amplitude ratio $\left(h / h_{0}\right)$ increases and $\beta$ decreases. This behavior can be correlated with the particle segregation (mainly $\mathrm{SiC}$ ) at bond interface. During TLPD bonding particles segregate at bond interface. Once the diameter of the specimen is reduced to $10 \mathrm{~mm}$ from $15 \mathrm{~mm}$
Table 3. Result of ultrasonic test.

\begin{tabular}{|c|c|c|c|}
\hline Bonding condition & $\begin{array}{c}\text { Specimen } \\
\text { length, } \mathrm{L} \\
(\mathrm{mm})\end{array}$ & $\begin{array}{c}\text { Amplitude } \\
\text { ratio, } \mathrm{h} / \mathrm{h}_{0}\end{array}$ & $\begin{array}{c}\beta \\
(\mathrm{dB} / \mathrm{m})\end{array}$ \\
\hline $\begin{array}{c}\text { As-received } \\
\text { composite } \\
\text { (no bonding) }\end{array}$ & 19.79 & 0.98 & 9 \\
\hline 20 minutes, $0.1 \mathrm{MPa}$ & 18.65 & 0 & $\infty$ \\
\hline 1 hour, $0.1 \mathrm{MPa}$ & 18.79 & 0.16 & 847 \\
\hline 2 hours, $0.1 \mathrm{MPa}$ & 19.19 & 0.48 & 332 \\
\hline 3 hours, $0.1 \mathrm{MPa}$ & 18.94 & 0.56 & 266 \\
\hline 6 hours, $0.1 \mathrm{MPa}$ & 19.17 & 0.61 & 224 \\
\hline 20 minutes, $0.2 \mathrm{MPa}$ & 18.46 & 0 & $\infty$ \\
\hline 1 hour, $0.2 \mathrm{MPa}$ & 18.85 & 0.58 & 251 \\
\hline 2 hours, $0.2 \mathrm{MPa}$ & 17.42 & 0.65 & 215 \\
\hline 3 hours, $0.2 \mathrm{MPa}$ & 18.59 & 0.73 & 147 \\
\hline 6 hours, $0.2 \mathrm{MPa}$ & 18.98 & 0.80 & 102 \\
\hline
\end{tabular}

for ultrasonic test, the interface width at central zone mainly represents the width of particle segregation. The width of particle segregation (interface width at central zone) is much higher than the $1 / 10$ th of the wavelength (Table 2) and, therefore causes significant scattering effect. Since the segregation is aligned perpendicular to the ultrasonic wave, waves are scattered all around causing attenuation. With increasing bonding time width of particle segregation decreases and accordingly attenuation also decreases due to reduced scattering effect. Attenuation coefficient $(\beta)$ approaches lower value at the completion of isothermal solidification ( $3 \mathrm{~h}$ bonding time) and homogenization of bond region ( $6 \mathrm{~h}$ bonding time). The lowering of attenuation coefficient with increasing bonding time is more pronounced at higher pressure $(0.2 \mathrm{MPa})$ due to faster decrease in width of particle segregation as compared to that at lower pressure (0.1 MPa).

\section{Conclusion}

(1) TLPD bonding process of 6061-SiCp composite occurs much faster than that of pure aluminium. Isothermal solidification takes about $3 \mathrm{~h}$ and bond region gets homogenized in $6 \mathrm{~h}$.

(2) In composite, the presence of defect-rich particle/ matrix interface and porosity makes diffusion process faster. In addition, during isothermal solidification most $\mathrm{SiC}$ particles are pushed by the moving solid/liquid interface. These particles segregate at the bond interface along with residual liquid. Simultaneously, under applied pressure the mass of residual liquid and segregated SiC particles at bond interface gradually moves towards periphery and ultimately flows out with increasing bonding time. This reduces the amount of residual liquid to be solidified. As a result the duration of isothermal solidification is reduced.

(3) The $\mathrm{CuAl}_{2}$ phase is found to be present at bond interface (segregation zone) as well as in the isothermally solidified zone. Pebble shaped $\mathrm{Fe}_{2} \mathrm{Al}_{5}$ phase of iron impurity segregates mainly at the bond interface.

(4) The Segregated particles at bond interface scatter ultrasonic wave causing attenuation. The extent of attenuation decreases as width of particle segregation decreases with increasing bonding time. The early stage of isothermal solidification is characterized by high attenuation with absence of back wall echo. Relatively lower attenuation indicates the completion of isothermal solidification and 
homogenization of the bond region.

\section{Acknowledgement}

Authors are grateful to Dr. V. K. Sinha, Professor, Department of Materials and Metallurgical Engineering, National Institute of Foundry and Forge Technology, Ranchi, India, for providing ultrasonic test facility and some useful technical discussions.

\section{REFERENCES}

1) D. Huda, M. A. El baradie and M. S. J. Hashmi: J. Mater. Process. Technol., 37 (1993), 529.

2) T. J. Lienert, W. A. Baeslack, J. Ringnalda and H. L. Fraser: J. Mater. Sci., 31 (1996), 2149.

3) M. B. D. Ellis: TWI J., 6 (1997), 69

4) W. I. Hall and F. Manrique: Scr. Met., 33 (1995), 2037.

5) M. F. Gittos and P. L. Threadgill: Proc. of Int. Symp. on Metal Matrix Composites III: Exploiting the Investment, Inst. of Metals, London, U. K., (1991), 1.

6) T. S. Luhman, R. L. Williams and K. B. Das: 4th Quarterly Progress Report, Army Materials and Mechanics Research Center, Watertown, Massachusetts, USA, (1983), 1.

7) J. H. Devletian: Weld. J., 66 (1987), 33.

8) R. S. Bushby and V. D. Scott: Mater. Sci. Technol., 11 (1995), 643.

9) A. A. Shirzadi and E. R. Wallach: Mater. Sci. Technol., 13 (1997), 135.

10) D. J. Field: Aluminium Alloys - Contemporary Research and Applications, London Academic Press, (1989), 523.

11) A. Urena, J. M. Gomez de Salazar and M. D. Escalera: Key Eng. Mater., (1995), 104.

12) Y. Natsume, K. Ohsasa, Y. Tayu, T. Momono and T. Narita: ISIJ Int., 43 (2003), 1976

13) P. G. Partridg and D. V. Dunford: J. Mater. Sci., 26 (1991), 2255.

14) R. S. Bushby and V. D. Scott: Mater. Sci. Technol., 9 (1993), 417.

15) T. K. Pal: Mater. Manuf. Process., 20 (2005), 717.

16) J. Huang, Y. Dong, Y. Wan, X. Zhao and H. Zhang: J. Mater. Process. Technol., 190 (2007), 312.

17) A. E. Dray: PhD thesis, University of Cambridge, (1985).
18) J. M. Papazian: Metall. Trans. A, 19A (1988), 2945.

19) P. K. Liaw, R. E. Shannon, W. G. Clerk, Jr., W. C. Harrigan, Jr., H. Jeong and D. K. Hsu: Mater. Chem. Phys., 39 (1995), 220.

20) Metals Handbook: Properties and Selection: Non-ferrous Alloys and Special-Purpose Materials, Vol. 2, 10th ed., ASM Int., The Materials Information Society, Materials Park, Ohio, USA, (1990), 102.

21) ASM Handbook: Alloy Phase Diagrams, Vol. 3, ASM Int., The Materials Information Society, Materials Park, Ohio, USA, (1992), 2.44.

22) Engineering Materials Handbook: Ceramics and Glasses, Vol. 4, ASM Int., The Materials Information Society, Materials Park, Ohio, USA, (1991), 30.

23) P. K. Rohatgi, R. Asthana and S. Das: Int. Met. Rev., 31 (1986), 115.

$24)$ D. S. Duvall, W. A. Owczarski and D. F. Paulonis: Weld. J., 53 (1974), 203.

25) I. Tuah-Poku, M. Dollar and T. B. Massalski: Metall. Trans. A, 19A (1988), 675.

26) S. Liu, D. L. Olson, G. P. Martin and G. R. Edwards: Weld. J., 70 (1991), 207.

27) Y. Nakao, K. Nishimoto, K. Shinozaki and C. Kang: Trans. Jpn. Weld. Soc., 20 (1989), 60.

28) M. Gallerneault, M. Kaya, R. W. Smith and G. W. Dellamore: Proc. Conf. on Extraction, Refining and Fabrication of Light Metals, Pergamon Press Inc., New York, USA, (1991), 69.

29) K. R. Van Horn: Aluminium, Properties, Physical Metallurgy \& Phase Diagrams, Vol. I, American Society for Metals, Metals Park, Ohio, (1967), 98.

30) A. R. Champion, W. H. Krueger, H. S. Hartman and D. K. Dhingra: Proc. of the 1978 Int. Conf. on Composite Materials-ICCM/2, TMS-AIME, New York, USA, (1978), 883.

31) D. J. Lloyd: Int. Mater. Rev., 39 (1994), 1

32) W. S. Miller and E. J. Humphreys: Scr. Metall. Mater., 25 (1991), 33.

33) R. J. Arsenault: Scr. Metall. Mater., 25 (1991), 2617.

34) N. A. Gjostein: Short Circuit diffusion, in "Diffusion", Papers Presented at a Seminar of the American Society for Metals, American Society for Metals, Metals Park, Ohio, (1972), 241.

35) G. Petzow and G. Effenberg: Ternary Alloys, a Comprehensive Compendium of Evaluated Constitutional Data and Phase Diagrams, VCH, Weinheim, 4, (1991), 475.

36) J. Krautkramer and H. Krautkramer: Ultrasonic Testing of Materials, 4th ed., Narosa Publishing House, New Delhi, (1993), 108. 